Gut, 1989, 30, 30-34

\title{
Relationships between symptoms, menstrual cycle and orocaecal transit in normal and constipated women
}

\author{
G K TURNBULL, D G THOMPSON, S DAY, J MARTIN, E WALKER, \\ AND J E LENNARD-JONES \\ From St Mark's Hospital and The London Hospital Medical College, London
}

SUMmary Because severe constipation is a disorder largely confined to young women, the possibility that menstrually related factors contribute to disturbed gastrointestinal motor function has been raised. It has also been reported that normal menstruating women show changes in upper gut transit between the follicular and luteal phases of the menstrual cycle and that patients with constipation show prolonged transit. We therefore studied relationships between symptom severity and orocaecal transit during the menstrual cycle in a group of 14 constipated women and a series of control groups comprising seven normal menstruating women, five postmenopausal women, and eight normal men, to determine whether phases of the menstrual cycle were associated with alteration in symptoms or transit. A regular menstrual cycle was reported by 13 of the 14 patients (range 26-30 days) and by all the menstruating female volunteers. Seven patients noted variation in constipation during the menstrual cycle, in all cases this comprised an improvement in symptoms just before or during menstruation. No consistent relationship between symptom severity and follicular or luteal phase was noted. Repeated orocaecal transit measurements in the four study groups showed no consistent differences $(>0 \cdot 05)$ between groups or during the menstrual cycle (mean change weeks 1-4, $-10 \pm 20 \mathrm{~min}$ ). These findings are inconsistent with the hypothesis of a progesterone related effect upon orocaecal transit in either normal or constipated women.

Severe constipation is a major clinical problem; it is distinguishable from the minor degrees of defecatory disability which are part of Western culture, by its severity, its chronicity and by its strong female preponderance. ${ }^{12}$ Because it is largely a disorder of women, the possibility that sex hormones are contributory is often raised. This view has been strengthened by the observations that many patients report menstrual cycle disorders, ${ }^{3}$ that progesterone can inhibit intestinal smooth muscle in vitro, ${ }^{4}$ and that constipation often occurs during normal pregnancy when circulating progesterone concentrations show a marked increase..$^{56}$

In addition, a recent survey of defecatory patterns in a normal population has suggested that women may pass harder stools in the luteal phase and have more prolonged gut transit. ${ }^{7}$ Further suggestive evidence is provided by an apparent relationship between upper gut transit as measured by the exhaled breath hydrogen sampling technique and menstrual

Address for correspondence: Dr D G Thompson, Department of Medicine, Hope Hospital, Eccles Old Road, Salford M6 8HD.

Received for publication 21 July 1988. cycle, transit being longest in the luteal phase when progesterone concentrations are highest. ${ }^{8}$ Similar transit delays have also been reported in a series of unselected constipated patients ${ }^{9}$ suggesting that the abnormality of intraluminal transport present in constipation may affect the small intestine as well as the colon.

Because of the relevance of these reports to the understanding of the pathophysiology of severe constipation, we undertook a series of studies into the relationships between symptom severity, menstrual cycle and orocaecal transit in a group of such patients. The results indicate that while a relationship between symptom severity and menstruation may exist, symptoms do not seem to be related to either the rate of upper intestinal transit or to the luteal phase of the menstrual cycle.

\section{Methods}

PATIENTS

Fourteen patients newly referred to St Marks Hospital for investigation of severe chronic constipa- 
tion, took part in the study. All conformed to the standard definitions of constipation ${ }^{2}$ - that is, passing fewer than three hard stools per week and excessive straining at stool. All were otherwise well and routine biochemical and haematological testing was normal. To exclude patients with either Hirschprung's disease or idiopathic megacolon from the group, a normal barium enema and an intact rectoanal inhibitory reflex were required before entry into the study. All drug therapy for constipation was discontinued at least 48 hours before, and during any experiment. Five patients were taking phased formulations of oral contraceptives, these were continued throughout the study on a 28 day cycle.

CONTROL SUBJECTS

Twenty one healthy adult volunteers took part in the studies as controls. All were free of gastrointestinal symptoms and had no past history of gastrointestinal disease. No subject was taking any medication at the time of the studies. Approval for the studies on normal subjects was obtained from the Local Ethics Committee and all individuals gave informed consent before the study.

RELATIONSHIPS BETWEEN CONSTIPATION AND MENSTRUAL CYCLE

At the time of recruitment to the study patients were questioned in detail about their symptoms and any reported relationships between symptom severity and menstrual cycle was noted. Patients also monitored their symptoms serially during the study period. At no time were they made aware of the nature of the hypothesis which was being tested. The normal controls were similarly interviewed to allow comparison of their defecatory habits with those of the patients.

WHOLE GUT TRANSIT

An assessment of the severity of constipation was made in all 14 patients by the radioopaque shape retention method. ${ }^{10}$ This previously developed and standardised technique involved the ingestion of 20 sections of barium impregnated polyethylene tubing $(3 \mathrm{~mm}$ diameter, length $0.5 \mathrm{~cm}$ ). Five days later a plain abdominal radiograph was taken to determine the number of markers retained in the gastrointestinal tract, retention of four or fewer markers at five days being taken to define the upper limit of the normal range. During the five days of study, patients ate high fibre diets of their own choice and avoided all drug therapy.

UPPER INTESTINAL TRANSIT

Eight of the constipated patients agreed to undergo measurement of orocaecal transit at least once during both halves of the menstrual cycle. Eight age matched healthy menstruating women were similarly studied. To avoid the possibility of introducing an order effect the timing of the first study in relation to the menstrual cycle was varied. Two additional control groups were studied, these were eight age matched men and five postmenopausal women, who performed four experiments at weekly intervals.

Orocaecal transit was measured in all individuals by determining the interval between ingestion of the test meal and the detection of a rise in exhaled breath hydrogen concentration using a hydrogen sensitive electrochemical cell (GMI Ltd, Renfrew, Scotland). After an overnight fast of at least 15 hours, a series of basal samples was collected at five minute intervals for 30 minutes. A standard mixed nutrient soup meal" (400 ml Chicken Soup, H J Heinz Ltd) containing $30 \mathrm{ml}$ lactulose (Duphalac, Duphar Ltd, Southampton, England) as a transit marker, was then ingested and serial exhaled breath samples were collected until an obvious rise in hydrogen concentration was observed. The precise end point of the study was then determined by subjecting the collected data points to cusum analysis ${ }^{12}$ taking as the end point of study a value which exceeded the basal values by two standard deviations.

ANALYSIS OF DATA

Differences between the four groups of transit data were tested for significance using a repeated measured analysis of variance procedure ${ }^{1.3}$ using the statistics package SPSS/PC +. This analysis compares both overall differences between the groups as well as changes at different times.

\section{Results}

BOWEL SYMPTOMS AND THE MENSTRUAL CYCLE Thirteen of the 14 patients reported a regular menstrual cycle with predictable onset of menstruation between 26 and 30 days. None of the normal menstruating subjects reported any menstrual irregularities and none had ever been aware of any change in defecatory pattern during the menstrual cycle. In contrast half the patients were aware that their symptoms varied with the menstrual cycle before and during the study. In all cases this change consisted of an improvement in the ease of defecation associated with softening of stool, either just before (one patient) or during (six patients) menstruation. The duration of the improvement ranged from two to seven days and was followed by a return of constipation until the next menstrual period.

None of the patients reported either a change in bowel frequency or increased difficulty in defecation during the second half of the menstrual cycle. 


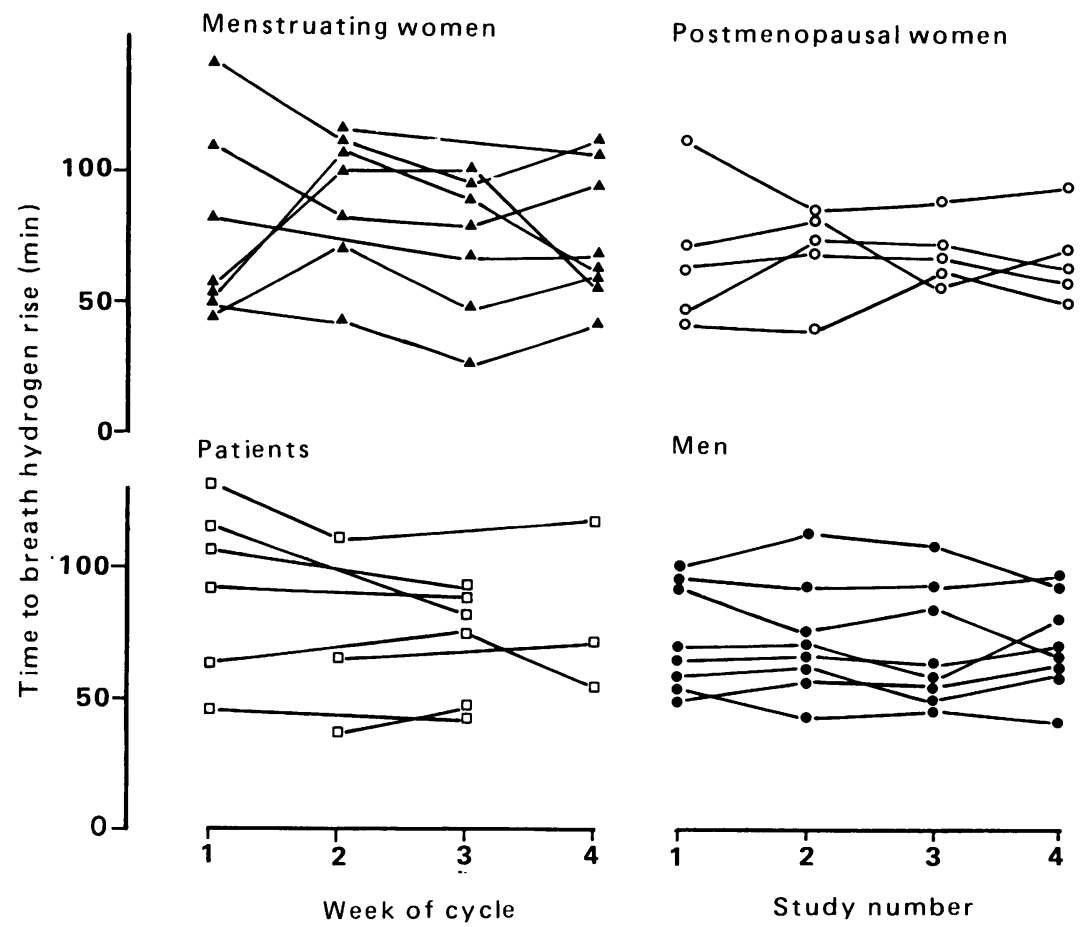

Fig. 1 Raw data from the upper intestinal transit studies in the four groups are shown. Each value represents the time to breath hydrogen rise for a given experiment.

Changes in constipation with menstrual cycle therefore consisted of an improvement during menstruation rather than a postovulatory deterioration.

In three of the 14 patients, symptoms had developed before the menarche and had been unaffected by the onset of puberty while in nine, constipation had postdated puberty by several years.

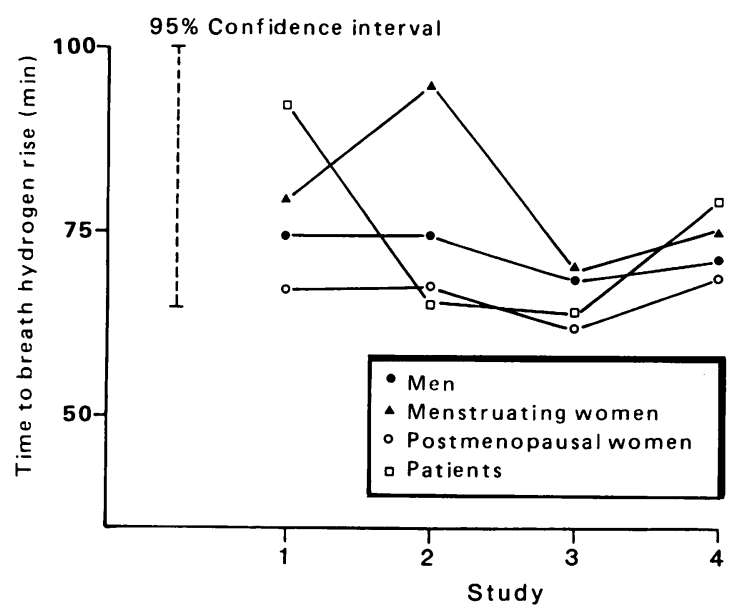

Fig. 2 Diagram shows the mean results from each group together with $95 \%$ confidence interval for any of the points.
Three of the patients had been pregnant. In all three, symptoms had remained unchanged during pregnancy.

\section{OROCAECAL TRANSIT}

The results of the orocaecal transit data are summarised in Figures 1 and 2. No consistent differences in transit were found between any of the groups studied ( $>>0.05$ for all analyses), and no order effect was noted. Confidence intervals were estimated for the data obtained for the patients and the menstruating controls. The confidence interval for the change between week 1 and week 4 was minus 10.5 minutes \pm 20 minutes - that is, ranging from a 30 minute reduction to a 10 minute increase. Because of the paucity of the data at week 4 for the patients it is not possible to calculate a time confidence interval for the change in this group. Assuming that the variation within patients is similar to that within menstruating controls, however, we would estimate a similar sized confidence interval.

\section{WHOLE GUT TRANSIT}

Nine of the 14 patients retained more than four of the radioopaque shapes at five days and thus satisfied the previously defined criteria for slow transit constipation by this method. ${ }^{2}$ There was no obvious 
Table Resultsofwholegutandorocaecaltransitstudies in the eight constipated patients

\begin{tabular}{|c|c|c|c|c|c|}
\hline \multirow[b]{2}{*}{ Patient } & \multirow[b]{2}{*}{ Age } & \multicolumn{2}{|c|}{$\begin{array}{l}\text { Marker retention at } \\
\text { five days }\end{array}$} & \multicolumn{2}{|c|}{$\begin{array}{l}\text { Orocaecal transit } \\
\text { (min) }\end{array}$} \\
\hline & & Follicular & Luteal & Follicular & Luteal \\
\hline 1 & 40 & 20 & - & 40 & 36 \\
\hline $2^{*}$ & 29 & - & 20 & 63 & $\begin{array}{l}85 \\
51\end{array}$ \\
\hline 3 & 30 & 8 & 18 & 65 & 70 \\
\hline 4 & 19 & 10 & - & 91 & 87 \\
\hline 5 & 41 & 0 & 3 & 32 & 42 \\
\hline $6^{*}$ & 28 & 2 & - & 118 & 69 \\
\hline 7 & 26 & 0 & 0 & 105 & 90 \\
\hline \multirow[t]{2}{*}{8} & 23 & 0 & 0 & 130 & 110 \\
\hline & & & & 100 & \\
\hline
\end{tabular}

*Indicates patients taking oral contraceptives.

correlation between whole gut transit time and orocaecal transit time (Table) in the eight patients.

\section{Discussion}

The results of our study indicate that while the menstrual cycle may, in some patients, be associated with an alteration of symptom severity, the pattern of change is not that which would be predicted by a progesterone related effect on smooth muscle.

This apparent improvement in symptoms during menstruation, as previously reported, ${ }^{14}$ is suggests that factors related to menstruation itself might be operative. One candidate mediator of such an effect is prostaglandin activity. The onset of menstruation is associated with a rise of uterine prostanoids ${ }^{16}$ particularly $\mathrm{PGF}_{2 \alpha}$ which are well known to have powerful stimulatory effects on both motor and secretory activity of the gut, ${ }^{17}$ and which might therefore exert gastrointestinal actions if they escape local degradation.

Our failure to find any consistent relationship between menstrual cycle and speed of upper intestinal transit, even in normal women, seems to be at variance with a previous study in which luteal prolongation was reported. ${ }^{8}$ Differences in results between this study and ours, may however, relate to the test meal used. Previous transit studies have characteristically used a test meal consisting of lactulose in water which is virtually isomolar and therefore unlikely to disrupt the fasting pattern of upper gut motility. ${ }^{18}$ Addition of nutrients to the lactulose as in our meal, however, is known to induce the characteristic fed motility pattern and reduces the intraindividual variability of serial transit studies. ${ }^{19}$ It is therefore possible that differences between reports, may relate to differences between effects of progesterone on fasted and fed motility. Although effects of progesterone on transit during the various phases of fasting motor activity are unknown, it is possible that progesterone may influence the function of the unstimulated gut more than the fed gut, when meal stimulated myenteric influences on motility and transit. might overwhelm any progesterone related relaxation of smooth muscle.

Review of previously reported effects of progesterone on human gut function provides conflicting data. In studies of upper gut transit, a luteal phase slowing was associated with blood progesterone concentrations within the normal luteal range of 40 $\mathrm{mg} / \mathrm{ml}$ and less, ${ }^{8}$ whereas studies during pregnancy showed transit delay only during the later stages by which time progesterone levels had exceeded nonpregnant values at least ten fold.$^{6}$ Other reports of progesterone related effects on gut function including oesophageal peristalsis, ${ }^{20}$ lower oesophageal sphincter pressure ${ }^{21-22}$, gastric emptying, ${ }^{2,-24}$ and gall bladder function, ${ }^{25}$ also appear to be equally inconclusive except in advanced pregnancy.

Taken together with the knowledge of progesterone concentrations required for in vitro responses,${ }^{4}$ it therefore appears that progesterone concentrations may need to exceed those found in non-pregnant women several fold before consistent effects on upper gut motor function are measurable.

As with most clinical experiments a negative answer in conjunction with a relatively small number of individuals studied raises the question of a false negative result. The confidence intervals obtained for the data, however, indicate that even if a difference in orocaecal transit does actually exist between phases of the menstrual cycle in either normal or constipated women, the magnitude of the differences are likely to be so small that they cannot be regarded as a realistic explanation of the reported changes in stool consistency or frequency.

More specific studies of colonic function particularly during and between menstruation are now required to explore more fully the nature of these cyclic symptom changes.

GKT was McLaughlin Fellow, Dalhousie University, Halifax, Nova Scotia, Canada. DGT was a Wellcome Trust Senior Lecturer in Medicine. The authors wish to acknowledge the secretarial assistance of Miss $\mathrm{H}$ Clarke and Ms J Rostron.

\section{References}

1 Anonymous. Constipation in young women [Editorial]. Lancet 1986; i: 778-9.

2 Preston D, Lennard-Jones JE. Severe chronic constipation of young women: idiopathic slow transit constipation. Gut 1986; 27: 41-8.

3 Preston DM, Rees LH, Lennard-Jones JE. Gynaecological disorders and hyperprolactinaemia in chronic constipation [Abstract]. Gut 1983; 24: A480. 
4 Gill RC. Bowes KL. Kingma YJ. Effect of progesterone on canine colonic smooth muscle. Gastroenterology 1985; 88: 1941-7.

5 Wald A, Van Thiel DH, Hoechstetter L, et al. Effect of pregnancy on gastrointestinal transit. Dig Dis Sci 1982; 27: $1015-8$.

6 Lawson M, Keru F, Everson GT. Gastrointestinal transit time in human pregnancy: prolongation in the second and third trimesters followed by postpartum normalization. Gastroenterology 1985; 89: 996-9.

7 Davies GJ, Crowder M, Reid B, Dickenson JWT Bowel function measurements of individuals with different eating patterns. Gut 1986; 27: 164-9.

8 Wald A, Van Thiel DH, Hoechstetter L, et al. Gastrointestinal transit: effect of the menstrual cycle. Gastroenterology 1981; 80: 1497-500.

9 Cann PA, Read NW, Brown C. Hobson N, Holdsworth CD. Irritable bowel syndrome: relationship of disorders in the transit of a single solid meal to symptom patterns. Gut 1983; 24: 405-11.

10 Hinton JM, Lennard-Jones JE, Young AC. A new method for studying gut transit times using radioopaque markers. Gut 1969; 10: 842-7.

11 O'Brien JD, Thompson DG, Day S, Burnham WR, Walker E. The effects of stress on human upper gastrointestinal transit and motility: a comparative study of two stimuli. Gut 1987; 28: 960-9.

12 Bissel AF. An introduction to cusum charts. Suffolk. Institute of Statistitians, 1984.

13 Armitage P. Statistical methods in medical research. Oxford: Blackwell, 1971.

14 Wyman JB, Heaton KW, Manning AP, Wicks ACB. Variability of colonic function in healthy subjects. Gut 1978; 19: 146-50.

15 Rees WDW, Rhodes J. Altered bowel habit and menstruation. Lancet 1976; ii: 475.
16 Rees MCP, Anderson AB. Demers LM. Turnbull AC. Endometrial and myometrial prostaglandin release during the menstrual cycle in relation to menstrual blood loss. J Clin Endocrinol Metab 1984; 58: 813-8.

17 Thor P, Konturek JW, Konturek SJ, Anderson JH. Role of prostaglandins in control of intestinal motility. Am J Physiol 1985; 248: 353-9.

18 Binfield P. DeBelder A. Thompson DG, Warren S. Wilson $M$, Wingate $D$. The influence of duodenal intraluminal osmolality on intestinal transit. J Physiol 1983; 343: 87-8.

19 La Brooy S, male P-J, Beavis AK, Misicwicz JJ. Assessment of the reproducibility of the lactulose $\mathrm{H}_{2}$ breath test as a measure of mouth to caecum transit time. Gut 1983; 24: 893-6.

20) Nelson JL, Richter JE, Johns DN, Castell DO, Centola GM. Esophageal contraction pressures are not affected by normal menstrual cycles. Gastroenterology 1984; 87: 867-71.

21 Fisher RS, Roberts GS, Grabowski CJ, Cohen S. Inhibition of lower esophageal sphincter circular muscle by female sex hormones. Am J Physiol 1978; 234: 243-7.

22 Dodds WJ, Dent J, Hogan WJ. Pregnancy and the lower esophageal sphincter. Gastroenterology 1978; 74: $1334-5$.

23 Horowitz M, Maddern GJ, Chatterton BE, et al. The normal menstrual cycle has no effect on gastric emptying. Br J Obstet Gynaecol 1985; 92: 743-6.

24 Schade R, Pelekanos MJ, Tauxe WN, Van Thiel DH. Gastric emptying during pregnancy. Gastroenterology 1984; 86: 1234.

25 Everson GT, McKuiley C, Lawson M, Johnson M, Kern F. Gallbladder function in the human female: effect of the ovulatory cycle, pregnancy and contraceptive steroids. Gastroenterology 1982; 72: 711-9. 